\title{
O TRAÇO, A LETRA E A BOSSA: ARTE E DIPLOMACIA EM CABRAL, ROSA E VINICIUS
}

Roniere Menezes

Doutor em Letras: Estudos Literários

\begin{abstract}
RESUMO
Este ensaio estabelece diálogos entre o discurso artístico-literário dos escritoresdiplomatas João Cabral de Melo Neto, João Guimarães Rosa e Vinicius de Moraes e o discurso das modernidades tardias no Brasil. Os textos analisados, publicados em meados do século 20, voltam-se para os espaços periféricos e para o homem comum, seu saber, sua inventividade.
\end{abstract}

\section{PALAVRAS-CHAVE}

Diplomacia, literatura, tradição, modernidade, homem comum

O objetivo deste ensaio é apresentar algumas reflexões a respeito das obras dos escritores-diplomatas João Cabral de Melo Neto, João Guimarães Rosa e Vinicius de Moraes, relacionando-as aos conflitos existentes entre tradição, modernidade e modernização, em meados do século 20, no Brasil. Nota-se, nas obras desses autores, o reflexo das alterações que a tensão entre modernidade e tradição gera na sensibilidade, no pensamento e no imaginário brasileiros a partir da segunda metade dos anos 1950, período em que o país elege a política desenvolvimentista como projeto estatal. Neste texto, referimo-nos às obras dos autores publicadas entre a segunda metade da década de 1950 e os primeiros anos da década de 1960, período em que a vontade hegemônica, racionalizante e estratégica da modernidade ganha novos sentidos no território nacional. O governo JK surge, na política brasileira, como marca histórica de um curto período durante o qual a imaginação criadora e o projeto de desenvolvimento se encontram, com suas coincidências e rupturas.

Em 1956, JK lançou o seu ambicioso Plano de Metas. São publicadas as novelas de Corpo de baile e o livro Grande sertão: veredas, de Rosa, que trabalhava no Itamaraty, no Rio de Janeiro, no período. Nos textos reunidos em Corpo de baile encontra-se a apresentação da vida miúda, destituída de direitos, da multidão sertaneja. O livro parece mais distante do 
projeto político republicano, perspectiva amplamente considerada nas análises de Grande sertão: veredas, livro em que se encena, alegoricamente, a fundação de uma República democrática que eliminaria as lutas de cangaço do interior do país. Corpo de baile suscita instigantes discussões a respeito da tensão sertão-cidade e de suas alterações na vida cotidiana do sertanejo.

No mesmo ano de 1956, João Cabral publica o volume Duas águas, pela José Olympio, reunindo os livros anteriores - entre os quais $O$ cão sem plumas e $O$ rio - e os inéditos Morte e vida severina, Paisagens com figuras e Uma faca só lâmina, este último dedicado a Vinicius. Nessa época, Cabral é transferido pelo Itamaraty para Barcelona, onde já trabalhara, passando a exercer o cargo de cônsul-adjunto.

Ainda em 1956, Vinicius volta de sua temporada como segundo secretário de embaixada em Paris e publica o poema "Um operário em construção”, no primeiro número da revista Para Todos, em que colabora a convite do escritor e amigo Jorge Amado. Nesse período, inicia relação com Tom Jobim, convidado pelo poeta para musicar textos de Orfeu da Conceição. A peça seria apresentada no Teatro Municipal do Rio de Janeiro, com atores negros, e contaria com cenário de Oscar Niemeyer. A bossa nova começava a nascer. Paralelamente ao aspecto solar e lírico de sua obra, Vinicius escreve, em meados do século 20, crônicas, poemas, peças teatrais e canções a respeito da vida suburbana carioca. Nesse sentido, podemos citar a peça As feras - chacina em Barros Filho (Tragédia "pau-de-arara" em três atos); a crônica “Operários em construção” e a canção "Pau-de-arara”, em parceria com Carlos Lyra. Vinicius compõe, ainda, em parceria com Tom Jobim, em 1960, a peça "Brasília, sinfonia da alvorada” - que seria executada na inauguração da nova capital federal - e escreve o script incompleto de "Ópera do Nordeste”, que teria músicas de Baden Powell.

Pela obra de Cabral, Rosa e Vinicius, transita uma multidão que circula pelo sertão, sempre cuidando de posses alheias, ou dele foge para chegar à cidade. Antes de se estabelecer, porém, já está partindo, habitando sempre espaços incertos. Mesmo no sertão, seus corpos, suas subjetividades e mediações sociais já começam a ser alterados pela nova "máquina mercante" incrementada com as modernidades tardias. Ao tratar da população das metrópoles, dado constante em Vinicius, verifica-se a presença de ambientes de trabalho temporários ou considerados menos nobres. Os espaços ligados à ideia de precariedade, de trânsito, de passagem, de instabilidade tornam-se marcantes nas criações desses autores. Há, nos textos, o desfile interminável das vidas inseguras que parecem exercer, nesses territórios da incerteza, sua única chance de levar adiante a existência. Transitam por intermináveis estradas; habitam os 
grotões, os casebres ao lado da casa-grande, os barracos de palafitas à beira do mangue, as favelas; equilibram-se como podem nos andaimes das construções e na prostituição das esquinas.

Os três escritores têm em comum o fato de terem sido diplomatas. Mais do que uma coincidência biográfica, o trabalho diplomático - visto como aproximação com a exterioridade de um sistema, abertura para o jogo de diferenças existentes na vida social, cultural e política - é tomado neste ensaio como um conceito que permite articular a leitura dos três autores. A diplomacia é focalizada como formação discursiva, uma política da escritura que se faz como ato intelectual.

A perspectiva diplomática é aqui entendida também como o procedimento, presente na produção artístico-literária dos três autores, de efetuar o "trânsito" entre discursos, assinalando espaços de enunciação negados pelo discurso dominante. O movimento da escritura diplomática pauta-se pela desterritorialização dos espaços discursivos conformados ao hábito repetitivo e à hierarquização dos campos de saber. Notamos o aparecimento, na obra dos autores, daquilo que expõe a produção silenciosa do capitalismo: a multidão de seres sem lugar, desalojados, desempregados, vagabundos, saltimbancos, prostitutas, seres desqualificados e desclassificados socialmente, em sua busca por condições de existência mais dignas ou mesmo em sua fuga do sistema repressor.

Nos textos pesquisados, nota-se a presença de elementos residuais, heterogêneos, não integrados à verdade alardeada pela produção incessante da modernidade. Esses signos de irredutibilidade mostram-se capazes de deslocar a percepção para os lugares mais recônditos da estrutura social. Os textos representam, sob múltiplos olhares, formas de comportamento, de sensibilidade e de raciocínio dos sujeitos menos favorecidos na escala social, em geral consideradas como destituídas de valor pela razão social pautada pelo pensamento lógico e objetivo. Por meio de posições deslocadas e descentradas, Cabral, Rosa e Vinicius buscam questionar os lugares hierárquicos tradicionais, impostos como naturais à ordem coletiva. A partir de fragmentos e resíduos, elaboram séries e coleções que demonstram a modelagem de um pensamento crítico pautado pela razão estética. Um aspecto importante na definição do perfil dos intelectuais brasileiros ligados ao trabalho diplomático é a corrosão, por eles promovida, da ideia de um regionalismo fechado, enrijecido, alheio às conexões com o mundo exterior. Ao mesmo tempo, contrariam as pretensões do Estado ligadas à ideia de unidade nacional. Os textos enfatizam as identidades heteróclitas do país, a multiplicidade de culturas e demandas sociais existentes no mapa brasileiro.

João Cabral, Guimarães Rosa e Vinicius de Moraes são escritores com trajetórias, reflexões e projetos distintos. Apesar dessas dissonâncias, acreditamos que, ao conjugar sua 
produção, é possível delinear novos arranjos, desvendando sentidos pouco abordados na análise de suas obras. Ao aproximar escritores de gêneros, estilos e posicionamentos tão diversos diante da obra e da vida, propomo-nos a quebrar algumas fronteiras, desierarquizar e espacializar conceitos, propiciar outras percepções para as obras. Em lugar da generalização, da aproximação entre escritores ou temáticas apenas por pontos de semelhança, o enfoque na diferença pode abrir a pesquisa a uma perspectiva mais diversificada do que aquela que norteia as análises comparadas tradicionais.

Se os diplomatas apresentam caminhos estéticos diversos, uma mesma preocupação perpassa suas obras: a tensão entre o discurso político do Brasil desenvolvimentista das elites urbanas e o discurso do Brasil arcaico, carente, rural ou suburbano. Na confluência entre propostas hegemônicas da modernidade tecnológica e capitalista e a posição de um país subdesenvolvido voltado, prioritariamente, para a produção agrícola, mas que pretende abrir-se à modernidade ocidental, os autores lançam um olhar cuidadoso. Construções artísticas e imagens contradisciplinares povoam os textos dos três escritores, que deixam vazar em sua escritura a reação da voz popular ao lugar incerto que lhe é atribuído. A categoria popular, em diálogo com os mecanismos tecnológicos e com o processo de fundação de uma sociedade sempre mais disciplinada, produtiva e desejosa de consumo em massa, é marca textual que une os escritores-diplomatas.

Em lugar das ferramentas restritas à objetividade técnica e ao saber operativo, os escritores em estudo - mesmo Cabral, com sua lógica de composição artística - apresentam a incerteza discursiva e a imaginação reflexiva como pontos nodais da atividade crítica. Ao transitarem pelas margens do pensamento científico e da racionalidade moderna oficial, questionam, a partir do espaço provisório da arte e da literatura, as instâncias do conhecimento normativo especializado. Ao ativarem, pela via da linguagem e da arte, a reflexão dos leitores, acabam por diluir a distinção tão demarcada entre o campo literário e a crítica cultural enquanto lugares produtores de conceitos a serem utilizados na análise social. Abrindo veredas e estabelecendo conexões ambíguas entre a realidade e os ambientes inventados, a arte contribui para o rompimento dos círculos fechados e vigiados de produção e recepção de sentidos; desse modo, constrói, por meio da teatralização simbólica do real, novas maneiras de politizar as relações cotidianas. A série dos cemitérios cabralinos - presente nos livros Paisagens com figuras, Quaderna e Dois parlamentos - é exemplo dessa fissura cavada nas páginas literárias, por onde se precipitam os elementos residuais que incutem mal-estar a um mundo de conformismo e homogenidade, traços característicos de uma sociedade desejosa de se reconciliar consigo mesma a cada novo projeto empreendido. 
O discurso literário de Cabral, Rosa e Vinicius contribui para desconstruir, a partir das margens, os valores absolutos veiculados pela voz oficial de um Estado cada vez mais inserido na ordem econômica e tecnológica internacional. Desviando o discurso para os espaços limiares do projeto de modernidade, esses escritores apresentam como fundamento de sua obra os migrantes, as pessoas do agreste, da Zona da Mata, dos Gerais, dos morros, das periferias, desafiando, porém, projetos vinculados ao conceito de "populismo" - em sua acepção tradicional - ou mesmo de "humanismo".

Nas obras dos escritores diplomatas, notamos a descrição de sertões e favelas que não são apenas lugares do abandono, da morte, da ingerência, da violência, nem somente o espaço de causos e de cantigas que devem ser retomados e recriados pela lente do artista intelectual urbano. O sertão e a favela aparecem como espaços de vida própria, onde existem descaso, disputa, empreendimento e planejamento. Os moradores criam, produzem, negociam, interagem. Há no homem sertanejo e suburbano preconceitos e visão de mundo limitada, mas também comunicação e rapidez de raciocínio, misturas de diversos saberes - como ocorre nos livros de cordel, nos desafios e nos sambas. Apesar de persistir o abandono do sertão e da periferia urbana, a produção de Cabral, Rosa e Vinicius abre-nos a percepção para formas de modernidades alternativas. As personagens demonstram que a fuga de territórios opressores exige uma força efêmera e positiva diante dos riscos.

Cabral, Rosa e Vinicius escrevem a lista dos deserdados, dos banidos, dos desempregados, das moças sem amparo, dos filhos sem pai, dos vadios e mendigos. Os textos às vezes apresentam raciocínios estranhos e gestos gratuitos ligados ao humor, à posse de objetos sem a menor serventia. Os autores provocam uma fissura no discurso coeso sobre a nação que se pretende desenvolvimentista e progressista. Ironicamente produzem homens, mulheres e crianças em série, muitos dos quais não se deixam capturar pelo sistema ou têm como meta existencial a intenção utópica de desviar-se de seus dispositivos disciplinares. Essas personagens expõem seu corpo e demonstram saberes pessoais e coletivos, transmitidos de geração a geração. Ao enfocarmos os saberes subalternos, visamos não a sua essencialização, mas a aproximá-los de outras formas de conhecimento, acentuando seu valor para a vida comunitária em forma de um ethos.

O discurso artístico-literário, em seu aspecto sociopolítico, volta-se, fundamentalmente, para a ênfase na comunidade daqueles que não se sentem incluídos, daqueles que estão destituídos do direito, da justiça, da cidadania. Os autores são viajantes de um Brasil perdido nos labirintos da modernização. Suas lentes buscam o solo concreto do país, mergulham sua inteligência e sensibilidade nesse lugar estranho, perigoso e de pouca 
visibilidade. Dentro dos conflitos comuns aí existentes, percorre um desejo de maior consideração pela experiência, pelo conhecimento das classes populares. A escritura diplomática comporta uma luta contra o risco de se enxergar no trabalhador nada mais do que um homem-máquina a ser talhado e moldado por uma lógica fria e serial, cerceadora das liberdades e capacidades humanas. O campo político, abrindo-se de modo pleno à racionalidade técnica, corre o risco de ver a massa populacional apenas como objeto vigiado e disciplinado para produzir mais e melhor, em menos tempo e a menor custo. Pela ótica de Cabral, Rosa e Vinicius, esses mesmos homens passam a ser articuladores de uma outra condição existencial, desejada pela produção estética, revelando outras possibilidades de leitura do Brasil.

\section{RÉSUMÉ}

Cette essai établie le dialogue entre le discours artistique-littéraire des écrivains-diplomates João Cabral de Melo Neto, João Guimarães Rosa et Vinicius de Moraes et le discours des modernités tardives au Brésil. Les textes analysés, publiés entre 1956 et 1961, évoquent les espaces périphériques et l’homme commun, son savoir, son inventivité.

\section{MOTS-CLÉ}

Discours artistique-littéraire, João Cabral de Melo Neto, João Guimarães Rosa, Vinicius de Moraes, discours des modernités tardives

\section{REFERÊNCIAS}

MELO NETO, João Cabral de. Obra completa. Rio de Janeiro: Nova Aguilar, 1999. MORAES, Vinicius de. Poesia completa e prosa. Rio de Janeiro: Nova Aguilar, 2004. ROSA, João Guimarães. Grande sertão: veredas. Rio de Janeiro: Nova Fronteira, 1986. ROSA, João Guimarães. Corpo de baile. Ed. comemorativa 50 anos (1956-2006). Rio de Janeiro: Nova Fronteira, 2006. 2 v. 